\title{
Do corticosteroids have a place in the management of rheumatoid arthritis in the elderly?
}

\author{
Richard B Williams \\ Consultant Rheumatologist, Rheumatology Department, Hereford County Hospital, Hereford HR1 2ER, UK
}

\section{Editorial}

Rheumatoid arthritis (RA) is the commonest inflammatory arthropathy with a prevalence of about $1 \%$ and an annual incidence of $36 / 100000$ for women and 14/100 000 for men, the incidence rising steeply with age in men and plateauing between 45 and 75 years of age in women. ${ }^{1-3}$ The prevalence rises with age, due to new cases and carry-over to the elderly age group from younger onset patients, and has been estimated to be as high as $4.9 \%$ in women over 65 years. ${ }^{4}$ In one recent study, $40 \%$ of RA patients attending a rheumatology clinic were over 60 years, $20 \%$ of whom developed RA after that age. ${ }^{5}$

The principles of drug treatment of rheumatoid arthritis are no different in the elderly from those applicable to other age groups, namely, that disease-modifying antirheumatic drugs (DMARDs) should be introduced early in the course of the disease with a view to providing good symptom relief and, it is hoped, improving outcome. However, the choice of drug may be influenced by the severity of the disease balanced against increasing risks of treatment related to age, intercurrent illness and concomitant medication.

In patients in otherwise good health and under the age of 75 years, it is reasonable to treat as for the younger age groups, namely, early use of sulphasalazine and, if this is ineffective or not tolerated, then the introduction of more potent (and toxic) agents such as gold or methotrexate. However, in patients over 75 years or with serious concomitant disease, the risk of many of the DMARDs is increased, largely due to decreased functional capacity of the marrow, liver and kidney, organs where many of the DMARDs exhibit their most serious toxicity. 6,7 Even if the risk of toxicity is not age-related, as is the case for gold, any side-effect may be more serious in an already frail patient. ${ }^{8}$

What is the optimal therapy for recent onset rheumatoid arthritis in the very elderly or frail patient? Recently, a significant reduction in the rate of joint erosion has been reported using prednisolone $7.5 \mathrm{mg}$ daily for two years in early RA (within two years of onset). ${ }^{9}$ There was also an initial improvement in symptoms and disability, although this was not sustained; no significant short-term side-effects were observed, but there was no attempt to assess long-term side-effects such as osteoporosis and atherosclerosis. The routine use of corticosteroids in young patients with early RA is not recommended because of concern over long-term side-effects and it is unfortunate that this much-publicized study has failed to address such an important issue. However, consideration of long-term side-effects in patients towards the end of their lives becomes less relevant than improving the quality of life in the relative short term. Also, RA in the elderly frequently presents with prominent polymyalgic symptoms, and in such patients there is often dramatic symptom relief using relatively low doses of prednisolone. There may be a case for managing early RA in frail and very elderly patients with $5-75 \mathrm{mg}$ prednisolone daily as the treatment of first choice or as an adjunct to DMARD therapy, but only after careful consideration of all the options by a rheumatologist.

\section{References}

1 Spector TD. Rheumatoid arthritis. Rheum Dis Clin N Am 1990; 16: 513-37.

2 Hochberg MC, Spector TD. Epidemiology of rheumatoid arthritis: update. Epidemiol Rev 1990; 12: 247-52.

3 Symmons DPM, Barrett EM, Bankhead CR et al. The incidence of rheumatoid arthritis in the United Kingdom: results from the Norfolk Arthritis Register. Br J Rheumatol 1994; 33: 735-39.

4 Engel A, Roberts J, Burch TA. Rheumatoid arthritis in adults: United States, 1960-1962. Vital o Health Statistics. Department of Health, Education and Welfare series 11, no. 17. Washington, DC: US Government Printing Office, 
1966.

5 Nesher G, Moore TL, Zuckner J. Rheumatoid arthritis in the elderly. J Am Geriatr Soc 1991; 39: 284-94.

6 O'Callaghan JW, Brooks PM. Disease modifying agents and immunosuppressive drugs in the elderly. Clin Rheumatol Dis 1986; 12: 275-89.

7 Kean WF, Anastassiades TP, Dwosh IL et al. Efficacy and toxicity of D-penicillamine for rheumatoid disease in the elderly. I Am Geriatr Soc 1982; 30: 94-100.

8 Kean WF, Bellamy N, Brooks PM. Gold therapy in the elderly rheumatoid arthritis patient. Arthritis Rheum 1983; 26: 705-11.

9 Kirwan JR. The effect of glucocorticoids on joint destruction in rheumatoid arthritis. $N$ Engl J Med 1995; 333: 142-46. 